\title{
Severe complications after negative pressure wound therapy in burned wounds: two case reports
}

This article was published in the following Dove Press journal:

Therapeutics and Clinical Risk Management

I July 2014

Number of times this article has been viewed

\author{
Haitao Ren' \\ Yuan $\mathrm{Li}^{2}$ \\ 'Department of Burns and Wound \\ Center, the Second Affiliated Hospital, \\ School of Medicine, Zhejiang \\ University, Hangzhou, People's \\ Republic of China; ${ }^{2}$ Department of \\ Ultrasound, Women's Hospital, School \\ of Medicine, Zhejiang University, \\ Hangzhou, People's Republic of China
}

\begin{abstract}
We present two typical cases of severe complications (sepsis and hemorrhage) after negative pressure wound therapy (NPWT) in burned patients. Necrotic tissues in some deep burn wounds are difficult to judge correctly and remove thoroughly. An electrically burned blood vessel looks "intact" but can easily break. Necrotic tissue or injured blood vessels when using NPWT are dangerous, both for causing sepsis and hemorrhage. This is the first article that reports the severe complications of NPWT in burned patients. It is imperative to heed indications and avoid contraindications. Proper preparation of wound beds, close observation, and sufficient irrigation are also crucial to avoid these severe complications, and there is an urgent need to substitute the central vacuum system with the low-pressure system.
\end{abstract}

Keywords: negative pressure wound therapy, complication, burn sepsis, bleeding, drainage

\section{Introduction}

Deep burn wounds require excision of eschar or eschar shaving operations. Negative pressure wound therapy (NPWT) is a new kind of vacuum-assisted wound closure technique, which can promote wound healing, ${ }^{1}$ increase the success rate of skin grafts, ${ }^{1}$ and reduce the labor of doctors. It has also been used to prepare the wound bed or secure the skin graft. ${ }^{2-5}$ Although there is a lack of evidence of NPWT promoting healing of burn wounds ${ }^{6}$ or chronic wounds, ${ }^{7}$ it is still widely used in burn units. Many articles have recently reported the advantages of NPWT for the treatment of burn wounds ${ }^{5,8}$ or other wounds, ${ }^{7,9-12}$ few studies have reported side effects that did occur, ${ }^{13,14}$ especially in burned patients.

There were two cases of severe bleeding and three cases of sepsis after NPWT in the past 3 years in our department (Department of Burns and Wound Center, the Second Affiliated Hospital, School of Medicine, Zhejiang University, Hangzhou, People's Republic of China). Herein, we present two typical cases of severe complications after treatment with NPWT in burned patients. More consideration to the side effects of treatment should be given to improve medical safety.

\section{Clinical data and case reports}

The two cases described in this report had no previous medical history of abnormal bleeding or severe immune dysfunction. In our department, the VSD (vacuum sealing drainage, one kind of NPWT widely used in the People's Republic of China) is usual practice and connected with the central vacuum system. The vacuum pressure was at approximately -150 to $-400 \mathrm{mmHg}$, and the drainage was continuous, not intermittent. Only white foam was used in the VSD system. The wounds were cleansed in turn with
Department of Ultrasound, Women's Hospital, School of Medicine, Zhejiang University, Xue shi Road I\#, Hangzhou 310006, People's Republic of China Email docliyuan@126.com 
normal saline (NS), hydrogen peroxide, povidone-iodine, and NS again during operation. The VSD dressing was changed every 4-5 days.

\section{Case I}

The first patient was a 34-year-old male suffering from $8 \%$ total body surface area, third- to fourth-degree electric flame burns. He was given the standard normal fluid resuscitation, early enteral nutrition, and regular dressing changes. On the fourth day after the burn, the excision of eschar in the right upper limb was performed. On the seventh day after the burn, heavy bleeding occurred. The patient heard a continuous, water-like sound from the drainage bottle. He saw lots of blood in the bottle and pressed the alarm button. The nurse and doctors came quickly and found that he was trembling, with a pale face and cold skin. The drainage bottle was full of fresh blood (approximately 1.5 L) and the bed dressing under his back was full of blood. The volume of blood loss was estimated to be more than $2 \mathrm{~L}$. The hemoglobin of his blood sample at that time was $5.1 \mathrm{~g} / \mathrm{dL}$ and his heart rate was $140 \mathrm{bpm}$. The blood pressure was $85 / 45 \mathrm{mmHg}$. Fluid resuscitation was conducted quickly. At the same time, a tourniquet cuff was used to prevent the bleeding and the NPWT material was removed. Next, the broken blood vessel was blocked, after which: $1.5 \mathrm{~L}$ balanced solution, $500 \mathrm{~mL}$ manufactured colloid, $400 \mathrm{~mL}$ plasma, and 1,500 mL red cell suspension were infused. The man recovered with a decrease in heart rate and increase of blood pressure. His hemoglobin increased to $8.5 \mathrm{~g} / \mathrm{dL} 1.5$ hours later.

\section{Case 2}

The second patient was a 58-year-old male suffering from 34\% total body surface area, deep, second-degree flame burns. He was given the standard normal fluid resuscitation, tracheal incision, early enteral nutrition, and regular dressing changes. Five days after injury, the eschar shaving with a dermatome in the lower limbs was carried out and the wound was covered with the NPWT dressing. Two days after the operation, the patient felt cold and his temperature rose to $39.5^{\circ} \mathrm{C}$. The local inflammatory reaction around the operation area was obvious. Peripheral blood, white blood cell count was $25 \times 10^{9} / \mathrm{L}$ $(2,500 / \mu \mathrm{L})$. Significant changes in serum procalcitonin and $\mathrm{C}$ reactive protein level were also found. His blood pressure was $80 / 65 \mathrm{mmHg}$ and his heart rate was $140 \mathrm{bpm}$. The patient was diagnosed with sepsis. The NPWT dressing was removed to check the wound. Approximately $100 \mathrm{~mL}$ of thick pus was found under the NPWT dressing. A standard sepsis treatment bundle, including fluid resuscitation and infusion of norepinephrine and glucocorticoids, was carried out according to the sepsis campaign. ${ }^{15}$ Meropenem and vancomycin were given to control the sepsis. The patient was saved and the blood bacterial culture was positive for methicillin-resistant Staphylococcus aureus. The antibiotic was adjusted according to the results of a drug sensitivity test. The patient eventually recovered.

The case occurred 2 years ago when VSD foams used in our department did not typically contain an irrigation tube; the so-called B-type VSD with buried irrigation tubes has been used since then in our clinic.

\section{Discussion}

NPWT is the application of negative pressure over a wound to promote wound healing. It has been widely used in treating chronic or acute wounds in recent years..$^{2-4,6,7,16}$ NPWT is a new strategy used in burn treatments..$^{5,6}$

The technique has some advantages including: aiding in the removal of wound edema and infectious and inflammatory materials, improving perfusion, and promoting the wound healing process. ${ }^{1}$ NPWT can inhibit the invasion and proliferation of Pseudomonas aeruginosa in burn-wounded tissue and decreased early mortality in a murine model of burn-wound sepsis. ${ }^{8}$ The NPWT system was a useful tool in securing autologous split-thickness skin grafts to the wound bed in pediatric burn patients. ${ }^{5}$ However, there is insufficient evidence of NPWT's effectiveness in treating burn wounds. ${ }^{6}$

NPWT also has severe complications. NPWT was indicated for some characteristics of the wounds in the described cases, ${ }^{1}$ however, there were also contraindications ${ }^{1}$ for NPWT in the two cases.

Bleeding was the first severe complication of NPWT in the described cases, and occurred because the foam prevented observation of the wounds, and the blood drained quickly when connected with the central vacuum system though a set of tubes and a drainage bottle. Exposure of a blood vessel is listed as a contraindication for NPWT use in guidelines. ${ }^{1}$ However, considering that NPWT has so many advantages, the doctors thought that complete hemostasis would prevent bleeding and discounted the risks. So, the fluke mind to avoid bleeding after a so-called complete hemostasis was one reason for the bleeding complication. Especially in the high-voltage-electricity burn case (Case 1), the membrane of injured blood vessels underwent string-of-beads morphologic changes, but the wall appeared "intact". An injured blood vessel will break, even with careful hemostasis. To avoid the bleeding risk, it is important to heed indications. In addition, 
the use of low pressure is a good strategy. The vacuumassisted closure system has a low-pressure drainage system, which is much safer but also much more expensive than a VSD system in the People's Republic of China. For economic reasons and because of inadequate low-pressure facilities, NPTW (VSD) is always connected with the central drainage system in Chinese hospitals until now. The vacuum pressure of this system is not constant and depends on the number of patients who are using it. The more patients sharing the central vacuum system, the lower the pressure. There is thus an urgent need to substitute the central vacuum system with the low-pressure system.

Sepsis was the second severe complication of NPWT in the reported cases. Necrotic tissue retention and the inadequate drainage of thick purulent secretions may be one reason that systemic infections occur. Presence of necrotic tissue is one of the contraindications of NPWT, so why did the doctors choose to use it in the end? The appearance of the burn wounds was somehow misleading. The eschar shaving was performed with a dermatome and cleansed in turn with NS, hydrogen peroxide, povidone-iodine, and NS was used again. Whether the necrotic tissue layer is cleaned thoroughly is judged by the operators with the naked eye in general, based on experience. Even an experienced doctor may miss a thin layer of necrotic tissue, which can lead to severe sepsis. Some wound exudates are heavy and mixed with blood, so drainage ducts may be very easily blocked. The vacuum falls to zero commonly because it is unstable. Any gaps in unit rounds may lead to ineffectiveness of the vacuum.

Irrigation is a very useful tool for reducing the risk of infections. However, a large volume of irrigation fluid can lead to leakage. When it happens, doctors will mend the membrane and usually reduce the volume of irrigations or even stop it altogether preventing the leakage. At that time, there are higher risks of infection. The importance of irrigation was not recognized in our clinic before these cases. Doctors perhaps believed it was just one option and were reluctant to prescribe it. After these experiences, our department now commonly uses $100-250 \mathrm{~mL}$ of fluid, including NS or benzalkonium bromide solutions, to irrigate wounds.

The two severe complications were both related to the central system. The too-high pressure led to bleeding and the too-low pressure led to fluid accumulation and infection.

To learn a lesson from these two typical cases and improve medical safety, it is important to review the indications and contraindications of NPWT in acute wounds.

The indications are as follows: open abdomen, sternal wounds, soft-tissue defects (trauma, necrotizing fasciitis, hidradenitis suppurativa, and extravasation injury), skin graft fixation, and burns. ${ }^{1}$ The contraindications include: presence of necrotic tissue, massive invasive infection, exposed cortical bone, and active bleeding from the wound site. ${ }^{1}$ Ignoring the contradictions can lead to severe complications. NPWT should be used with thorough hemostasis and debridement. If there is any potential bleeding risk or any suspicion of necrotic tissue retention, NPWT should not be used or should only be used with the highly likely side effects in mind. It is also very important to pay attention to the characteristics of drained fluid, the appearance of NPWT dressing, the inflammatory reaction around the wound, and changes in inflammation biomarkers. Electric burn wounds may contain injured blood vessels, which have a high risk of breaking. NPWT should be used carefully in patients with electric burns.

\section{Limitations}

The present study was limited by the number of cases. We did not perform other control treatments or prospective studies.

\section{Conclusion}

Sepsis and hemorrhage are potential severe complications of NPWT. Following indications guidance and avoiding contraindications are important. In addition, proper preparation of the wound beds, close observation, and sufficient irrigation are crucial for avoiding complications. There is an urgent need to substitute the central vacuum system with the low-pressure system.

\section{Acknowledgments}

Professor Chunmao Han and other colleagues in Department of Burns and Wound Center, the Second Affiliated Hospital, School of Medicine, Zhejiang University, Hangzhou, People's Republic of China. Both authors contributed equally to this work and should be considered co-first authors.

\section{Disclosure}

The authors report no conflicts of interest in this work.

\section{References}

1. Bovill E, Banwell PE, Teot L, et al; International Advisory Panel on Topical Negative Pressure. Topical negative pressure wound therapy: a review of its role and guidelines for its use in the management of acute wounds. Int Wound J. 2008;5(4):511-529.

2. Armstrong DG, Lavery LA; Diabetic Foot Study Consortium. Negative pressure wound therapy after partial diabetic foot amputation: a multicentre, randomised controlled trial. Lancet. 2005;366(9498):1704-1710.

3. Blume PA, Walters J, Payne W, Ayala J, Lantis J. Comparison of negative pressure wound therapy using vacuum-assisted closure with advanced moist wound therapy in the treatment of diabetic foot ulcers: a multicenter randomized controlled trial. Diabetes Care. 2008;31(4):631-636. 
4. Shankaran V, Brooks M, Mostow E. Advanced therapies for chronic wounds: NPWT, engineered skin, growth factors, extracellular matrices. Dermatol Ther. 2013;26(3):215-221.

5. Hoeller M, Schintler MV, Pfurtscheller K, Kamolz LP, Tripolt N, Trop M. A retrospective analysis of securing autologous split-thickness skin grafts with negative pressure wound therapy in paediatric burn patients. Burns. In press 2014.

6. Dumville JC, Munson C. Negative pressure wound therapy for partialthickness burns. Cochrane Database Syst Rev. 2012;12:CD006215.

7. Dumville JC, Hinchliffe RJ, Cullum N, et al. Negative pressure wound therapy for treating foot wounds in people with diabetes mellitus. Cochrane Database Syst Rev. 2013;10:CD010318.

8. Liu Y, Zhou Q, Wang Y, et al. Negative pressure wound therapy decreases mortality in a murine model of burn-wound sepsis involving Pseudomonas aeruginosa infection. PloS One. 2014;9(2):e90494.

9. Gupta S. Optimal use of negative pressure wound therapy for skin grafts. Int Wound J. 2012;9 Suppl 1:40-47.

10. Streubel PN, Stinner DJ, Obremskey WT. Use of negative-pressure wound therapy in orthopaedic trauma. J Am Acad Orthop Surg. 2012;20(9):564-574.

11. Isaac AL, Armstrong DG. Negative pressure wound therapy and other new therapies for diabetic foot ulceration: the current state of play. Med Clin North Am. 2013;97(5):899-909.
12. Upton D, Stephens D, Andrews A. Patients' experiences of negative pressure wound therapy for the treatment of wounds: a review. JWound Care. 2013;22(1):34-39.

13. Sjögren J, Gustafsson R, Nilsson J, Lindstedt S, Nozohoor S, Ingemansson R. Negative-pressure wound therapy following cardiac surgery: bleeding complications and 30-day mortality in 176 patients with deep sternal wound infection. Interact Cardiovasc Thorac Surg. 2011;12(2):117-120.

14. van Wingerden JJ, Segers P, Jekel L. Major bleeding during negative pressure wound/VAC ${ }^{\circledR}$ - therapy for postsurgical deep sternal wound infection - a critical appraisal. J Cardiothorac Surg. 2011;6:121.

15. Dellinger RP, Levy MM, Rhodes A, et al: Surviving sepsis campaign: international guidelines for management of severe sepsis and septic shock: 2012. Crit Care Med. 2013;41(2):580-637.

16. Stannard JP, Robinson JT, Anderson ER, McGwin G Jr, Volgas DA, Alonso JE. Negative pressure wound therapy to treat hematomas and surgical incisions following high-energy trauma. JTrauma. 2006;60(6): 1301-1306.
Therapeutics and Clinical Risk Management

\section{Publish your work in this journal}

Therapeutics and Clinical Risk Management is an international, peerreviewed journal of clinical therapeutics and risk management, focusing on concise rapid reporting of clinical studies in all therapeutic areas, outcomes, safety, and programs for the effective, safe, and sustained use of medicines. This journal is indexed on PubMed Central, CAS,

\section{Dovepress}

EMBase, Scopus and the Elsevier Bibliographic databases. The manuscript management system is completely online and includes a very quick and fair peer-review system, which is all easy to use. Visit http://www.dovepress.com/testimonials.php to read real quotes from published authors.

Submit your manuscript here: http://www.dovepress.com/therapeutics-and-clinical-risk-management-journal 